\title{
Considerações sobre a antipolítica de Nietzsche: a primazia da cultura em oposição a política moderna
}

\section{Considerations on Nietzsche's antipolitics: the primacy of culture in opposition to modern politics}

\author{
WAGNER SOARES FRANÇA ${ }^{1}$
}

\begin{abstract}
Resumo: Este trabalho tem como objetivo elucidar a temática da questão política no pensamento de Nietzsche. Para tal é imprescindível recorrer a abordagem de certas noções do corpus nietzschiano; a fim de elucidar como o filósofo estabelece sua noção de antipolítica, o que envolve explicar as concepções de "pequena política" e "grande política", no intuído de esclarecer como o filósofo opera essas noções através da crítica realizada aos conceitos basilares da democracia ocidental.
\end{abstract}

Palavras-chave: Política. Hierarquia. Cultura.

Abstract: This paper aims to elucidate the theme of the political question in Nietzsche's thinking. For this it is essential to resort to the approach of certain notions of the Nietzschean corpus; in order to elucidate how the philosopher establishes his notion of antipolitics, which involves explaining the conceptions of "small politics" and "great politics", in an attempt to clarify how the philosopher operates these notions through the critique of the basic concepts of Western democracy.

Keywords: Politics. Hierarchy. Culture.

"A cultura deve seus valores mais elevados aos períodos de fraqueza política."

$(\mathrm{HH} \S 465)$

"Todas as grandes épocas da cultura foram, politicamente, épocas pobres."

(Nachlass/FP setembro de 1888 1911)

Este trabalho tem o intuito de elencar algumas considerações sobre $\mathrm{o}$ pensamento político de Nietzsche, sem a pretensão de esgotá-lo ou de posicionar o pensamento nietzschiano em alguma corrente clássica da reflexão política. Pretende-se, contudo, apontar algumas críticas e possíveis 'soluções' concernentes a essa temática, salientado como o pensador compreende as concepções de 'pequena política' e de 'grande política', esta última refere-se a uma concepção ampla de cultura englobando o aspecto político. A estrutura referente aos pontos constituintes desse texto, assim como seus movimentos, pretende elucidar como Nietzsche compreende as noções de hierarquia, aristocracia, Cultura e Estado, bem como no tocante ao surgimento da moralidade essencial na sua compreensão da

\footnotetext{
${ }^{1}$ É bacharel em Filosofia pela UFPel (2009-2013) e Mestre em Filosofia também pela mesma instiuição. E-mail: wagnersf@gmail.com
} 
política europeia do XIX. Entretanto não pretendemos apenas nos deter em uma exposição exegética desses pontos, mas sim, averiguar em que sentido sua crítica à política moderna é pertinente atualmente; bem como contextualizar que os principais pressupostos políticos do ocidente, apesar da reflexão política contemporânea considerar a inviabilidade dessa correlação, são oriundos de instâncias de cunho religioso/dogmático.

A partir dessas afirmações, devemos abdicar a Nietzsche o estatuto de pensador político como o próprio parece nos incitar, ou talvez porque não propunha nenhuma teoria e nenhum programa político apropriado? Ou, ao contrário, seria possível apontar em seus escritos teses, "ideias" especificamente políticas? Para responder tais questões deve-se primeiramente analisar como o filósofo compreende a noção de política na segunda metade de século XIX e mesmo no interior da história da Filosofia. Para tal, alguns escritos de Nietzsche se fazem importes nessa perspectiva, a saber: os textos do segundo período ${ }^{2}$, marcados pelo 'filosofar histórico', onde julga encontrar os elementos formadores constituintes do Estado e dos valores democráticos assentados no ocidente, tais como a Liberdade, responsabilidade, normatividade, subjetividade e justiça, para posteriormente averiguarmos nos textos do último período, indícios do que entende por 'grande política'.

Nietzsche caracteriza-se como um pensador "antipolítico" no último estágio de seu período tardio. Nos seus escritos existem diversas declarações que abrangem a esfera política, dentre as quais muitas carecem de aprofundamento conceitual, e outras parecem ao menos descrever as grandes linhas do que o próprio filósofo compreende como política. Esta concebida como aquela onde os indivíduos são postos hierarquicamente no interior de uma comunidade, concedendo a primazia dos indivíduos ao invés do prevalecimento do Estado e dos valores democráticos, como veremos. Tais valores conduzem em última instância à "igualação" e, por conseguinte, à "mediocrização" do homem moderno. O pensamento político nietzschiano, grosso modo, ambiciona a primazia dos valores de tipo "aristocrático", sendo entendido por Nietzsche como uma instância naturalmente assimilada no homem para exercer a 'grande política'; o que remete a exigência de novos valores, sendo estes não somente intelectualmente pensados, mas incorporados. Com a intensão se satisfazer a proposta do trabalho, o mesmo possui dois movimentos, um primeiro abordando a 'pequena política' e um segundo dedicado a 'grande política'.

\footnotetext{
${ }^{2}$ A tradicional divisão dos períodos de Nietzsche, aqui adotada é mencionada por Scarlett Marton em sua obra "Nietzsche: Das forças cósmicas aos valores humanos", a saber: de 1870 a 1876 - o período ou período romântico; de 1876 a $1882-2^{\circ}$ período ou período do positivismo cético e por fim, de 1882 aos primeiros dias de $1889-3^{\circ}$ período, ou período da transvaloração.
} 


\section{Considerações iniciais sobre a 'pequena política'}

Para o filósofo toda teoria política como sua própria noção está fundamentada no privilégio da comunidade em detrimento da individualidade daqueles que a constituem, "o cuidado do todo deve prevalecer sobre aquele de suas partes" (DENAT, 2013, p. 49). A partir de perspectivas idealistas desde Platão $^{3}$ e intensificadas pela modernidade, a política pode ser identificada como o cuidado ou a manutenção do bem comum, do qual todo interesse particular está sujeitado em prol da comunidade. Concomitantemente a comunidade defende-se com um constante cuidado de proteção e conservação de seu status quo, pois é pensada na coletividade de seus indivíduos como uma comunidade particular e distinta das outras, necessitando por isso de sua preservação. Tais preferências basilares que norteiam permanentemente as formas clássicas da reflexão política constituem dois modos de pensar essa problemática a partir de Nietzsche, de um lado, pensar a esfera política moderna/contemporânea como consequência de uma necessidade de simplificação, pois é mais simples pensar a suposta unidade do todo que a singularidade de cada indivíduo; por outro lado, como resultado de uma necessidade de proteção da comunidade, que ao supervalorizar o todo, adquiri a capacidade de se proteger de indivíduos mais potentes, estes compreendidos pela política vigente que prioriza o todo, como maus, perigosos e imorais. Essa perspectiva tende enfim, a aniquilar a possibilidade de toda efetivação de qualquer singularidade, de toda exceção, em suma, abolir tudo que há de mais individual no homem:

Parece agora que faz bem a todos ouvir dizer que a sociedade está em vias de adaptar o indivíduo às necessidades gerais e que $a$ felicidade e ao mesmo tempo o sacrifício do indivíduo consistem em sentir-se como um membro e instrumento útil do todo; [...]. Não se quer nada menos - quer se confesse ou não - do que uma

\footnotetext{
3 Segundo Nietzsche, a filosofia desde Platão passou a ser pensada, estruturada e fundamentada pelo ideal, isto é, um pensamento caracterizado como ciência primeira por ter como objetivo, a demonstração de um princípio fundante de todos outros princípios e posteriormente com a ascensão do cristianismo, essa característica, consolida-se como modo de pensar hegemônico no ocidente, pois admite, em seu cerne argumentativo, a existência da substancialidade e da universalidade de instâncias como a razão, a verdade, o conhecimento, a justiça e a liberdade, por exemplo, sendo essas noções centrais na história do pensar. Talvez a mais importante dentre estas, no interior da filosofia ocidental é a plena capacidade racional atribuída ao homem, ou seja, a razão enquanto faculdade independente do corpo, podendo intervir neste livremente na relação de mando e obediência, ao sujeitar os impulsos no homem. Da mesma forma, a inteligibilidade de verdades absolutas, somente pode ser fundamentada ou 'acessada' por meio da razão. Nessa perspectiva, tanto o fundamento ultimo da ação, quanto as pretensões absolutistas de verdade, seriam determinadas pela razão ou em última instância engendradas por ela. Tal posição é retirada de "Para Além de Bem e Mal" (BM. §191) (NIETZSCHE, 2002, p. 91), onde lê-se: "Platão, mais inocente nessas coisas, e despido de astucia plebéia, quis, com toda a energia - a maior energia que um filósofo já empregara! - provar a si mesmo que razão e instinto se dirigem naturalmente a uma meta única, ao bem, a "Deus"; e desde Platão todos teólogos e filósofos seguem a mesma trilha".
} 
transformação radical, e mesmo enfraquecimento e supressão do indivíduo: não se cansam de enumerar e acusar tudo que há de mal e hostil, de perdulário, de dispendioso (...) (M/A §132) ${ }^{4}$.

Nietzsche afirma que a debilitação progressiva dos indivíduos por meio de sua uniformização tem como consequência última o enfraquecimento do todo; o filósofo a esse respeito sustenta que a tradicional exigência política concernente a noção de bem comum possui uma contradição interna, como exposta no § 43 de Além de bem e mal: “Bem' não é mais bem quando é o vizinho que a tem na boca. E, desse modo, como poderia haver um 'bem comum'?! A palavra contradiz a si própria: o que pode ser comum sempre tem pouco valor. " É a partir desse contexto, a necessidade de compreender a crítica nietzschiana ao Estado considerado como um fim em si, promovendo o bem comum que "não cessa de sacrificar um grande número de talentos superiores no 'altar da pátria' ou da 'ambição nacional” (MA $\mathrm{I} / \mathrm{HH}$ I). Por essa mesma razão, é necessário, afirma o filósofo muitas vezes, " $O$ mínimo de Estado possível”(MAI/HHI §473,), ou no mínimo, é necessário compreender que: "A finalidade do Estado jamais deve ser o Estado, mas sempre os indivíduos" (Nachlass $1876 \quad 17$ [17]). É imprescindível, entretanto, algumas ponderações sobre a concepção nietzschiana acerca do Estado e de sua formação, no sentido de compreender sua antipolítica.

Nietzsche sustenta que os homens não passaram a conviver em sociedade por intermédio de um contrato ou alguma disposição interna para a sociabilidade. A visão nietzschiana de formação do Estado não possui caráter contratualista ou naturalista para o exercício da política; a própria definição do surgimento do Estado e da moralidade, em Nietzsche provém da coerção, da força e do modo como foi imposta a partir de um processo imperioso que promoveu, e ainda promove no homem, a crença ilusória de uma tendência natural para viver em sociedade, como sustenta Nietzsche:

A moralidade é antecedida pela coerção, e ela mesma é ainda por algum tempo coerção, à qual a pessoa se acomoda para evitar o

\footnotetext{
${ }^{4}$ Este trabalho adota como convenção para a citação das obras de Nietzsche, a proposta pela edição crítica Colli/Montinari. Será utilizada a versão online das obras editada por Paolo D'lorio: NIETZSCHE, Friedrich. Digital critical edition of the complete works and letters, based on the critical text by G. Colli and M. Montinari, Berlin/New York, de Gruyter 1967-, edited by Paolo D'Iorio. As siglas em alemão são acompanhadas pelas siglas em português acrescidas do algarismo indicando o respectivo aforismo, tal como é adotado como convenção no periódico Cadernos Nietzsche, a saber: MAI/HHI - Menschiches Allzumenschliches (v.1) (Humano, demasiado humano (v.1)) - 1878; M/A Morgenröte (Aurora) - 1880-1881; FW/GC - Die fröhliche Wissenschaft (A gaia ciência) - 1881 e 1886; JGB/BM - Jenseits von Gut und Böse (Além do bem e do mal) - 1885 - 1886; GD/CI - GötzenDämmerung (O crepúsculo dos ídolos) - 1888; AC/AC - Der Anticrhist (O Anticristo) - 1888; EH/EH Ecco Homo (Ecce Homo) - 1888.
} 
desprazer. Depois ela se torna costume, mais tarde obediência livre, e finalmente quase instinto: então, como tudo o que há muito tempo é habitual e natural, acha-se ligada ao prazer - e se chama virtude (MAI/HHI §99).

Itaparica reconstrói esse processo coercitivo envolvendo o aspecto coercitivo da moralidade defendendo que "a passagem para o estado não se dá pelo contrato, mas pela coerção, e com ela vemos o caminho que leva à moralidade: coerção (para evitar desprazer e provocar bem-estar) $\rightarrow$ costume $\rightarrow$ obediência livre (racional) $\rightarrow$ quase instinto (hábito) $\rightarrow$ prazer nas ações "boas" (virtude)" (ITAPARICA, 2013, p. 76). Como exposto, a história dos sentimentos morais converge na relação de bemestar, o que não difere de uma posição estritamente egoísta, segundo o filósofo. Assim, a tradição metafísica historicamente empreendeu justificar e fundamentar as qualidades humanas e o conhecimento sob a esfera do transcendente, dissociando qualquer elemento humano, de cunho fisiológico (prazer/desprazer) como fundamento último.

Esse aspecto em assumir o exercício da moralidade como algo relacionado ao hábito tornou possível a Nietzsche refletir pela via oposta, ou seja, pela própria análise dos elementos fundantes da moral, questionando porque o contrário não seria aceitável. O que faz de algo dito como imoral, errado e ameaçador, contrariando os costumes uma vez estabelecidos pelo hábito? A linha argumentativa exposta por Nietzsche para responder essa questão, sustenta que:

Não acusamos a natureza de imoral quando ela nos envia uma tempestade e nos molha; por que chamamos de imoral o homem nocivo? Porque neste caso supomos uma vontade livre, operando arbitrariamente, e naquele uma necessidade. Mas tal diferenciação é um erro. Além disso, nem a ação propositadamente nociva é considerada sempre imoral; por exemplo, matamos um mosquito intencionalmente e sem hesitação, porque o seu zumbido nos desagrada; condenamos o criminoso intencionalmente e o fazemos sofrer, para proteger a nós e à sociedade. No primeiro caso é o indivíduo que, para conservar a si mesmo ou apenas evitar um desprazer, faz sofrer intencionalmente; no segundo é o Estado. Toda moral admite ações intencionalmente prejudiciais em caso de legítima defesa: isto é, quando se trata da autoconservação! (MAI/HHI §102).

O filósofo identifica que a moral e o Estado provêm do hábito estimulado pela autoconservação, remetendo em última instância a relação de prazer e desprazer. Para Nietzsche o Estado e a moralidade se exercem e se mantém pelo critério de convergência das ações produzirem prazer tanto no indivíduo como no grupo, nesse caso, devem refletir os costumes de uma comunidade moral, por meio de ações "boas", “agradáveis", “uteis" e "prazerosas". Para o autor de Humano, demasiado humano, essas 'qualidades' não possuem lugar no escopo crítico de sua metodologia 
filosófica que tem por base compreender essas questões primeiramente a partir da psicologia para posteriormente englobá-la em uma noção abrangente de fisiologia5.

Não acusar eventos naturais de imorais, para Nietzsche, remete a crença na substancialidade e na realidade metafísica da vontade livre do homem, por isso aquele que age de forma 'errada' ou 'maldosa' é identificado como imoral, pois poderia ter escolhido de outro modo, o que não acontece com eventos naturais. Nietzsche ao comparar ações morais e imorais, radicaliza essa questão afirmando que "se admitimos a legítima defesa como moral, devemos também admitir todas as expressões do chamado egoísmo imoral (Unmoralische): causamos a dor, roubamos ou matamos a fim de nos conservar ou nos proteger, a fim de prevenir uma desgraça pessoal” (MAI/HHI §104). Os atos envolvendo aspectos da 'legítima defesa' para Nietzsche são por definição, ações egoístas que presam a autoconservação, a esse respeito afirma, "todas as "más" ações são motivadas pelo impulso de conservação ou, mais exatamente, pelo propósito individual de buscar o prazer e evitar o desprazer; sendo derivadas da necessidade e por isso não podem, segundo Nietzsche, serem classificadas como más. "Causar dor em si" não existe, salvo no cérebro dos filósofos, e tampouco "causar prazer em si"” (MAI/HHI §99), o que Nietzsche quer dizer, é que tanto a autopreservação do indivíduo como de uma comunidade deriva do impulso egoísta para a conservação, que é anterior a qualquer forma de pensamento deliberativo envolvendo uma escolha livre. As ações ditas de más, egoístas e incorretas mesmo visando a conservação são compreendidas como erradas e ameaçadoras pela moral vigente, ou seja, é com base no status moral que uma ação é definida de moral ou imoral. Em Aurora, Nietzsche defende esse ponto de vista sustentando que a imoralidade sempre tem uma conotação perversa ou maléfica quando os indivíduos tendem a realizar ações em seu próprio benefício no sentido de autopreservação, pois, "sob a total desaprovação dos representantes da moralidade do costume ${ }^{6}$ - afastam-se da comunidade, como imorais, e são maus na mais profunda acepção” (M/A §9).

De acordo com a perspectiva nietzschiana a 'pequena política' estrutura-se de modo a impossibilitar a existência de indivíduos que possam agir em conformidade com sua 'natureza'. Superficialmente pode-se pensar que a política em Nietzsche

\footnotetext{
${ }^{5}$ A fisiologia não pode ser compreendia como a visão da ciência biológica tem desse termo, segundo Frezzatti, o fisiológico em Nietzsche "não pode ser substituído como sinônimo pelo termo "biologia", pois ele passa a considerar não apenas corpos vivos, mas também o âmbito inorgânico e das produções humanas, tais como Estado, religião, arte, filosofia, ciência, etc. Em outras palavras, a "fisiologia", nesse sentido, extrapola o âmbito do biológico, mas ainda se refere a uma "unidade", ou seja, a um conjunto de forças ou impulsos. O corpo ou a unidade orgânica nada mais é, para Nietzsche, do que um conjunto de impulsos. Sendo este conjunto bem hierarquizado, ou seja, sendo tornado uma "unidade" (FREZZATTI, 2004, 117-118).

${ }^{6}$ Sobre esse aspecto referente a eticidade e o processo de formação da moralidade, indicamos o estudo da Prof. Vânia Azeredo intitulado "Eticidade do Costume: A Inscrição do Social no Homem", publicado na revista Dissertatio n.25.
} 
consiste na efetivação das subjetividades que compõe uma sociedade, onde todos poderiam exercer suas 'vontades' 'livremente' (o que não existe, pois, a filosofia nietzschiana tem como 'critério' a hierarquização dos indivíduos como veremos); essa interpretação além de equivocada não abrange a profundidade da crítica nietzschiana ao modo como a sociedade moderna está politicamente estruturada. Para Nietzsche é preciso uma estrutura política mínima capaz de incluir em seu domínio o âmbito pulsional dos indivíduos. O problema apontado pelo filósofo diz respeito a inviabilidade da política moderna englobar as pulsões nas relações entre indivíduos, uma vez que, promove apenas a manutenção do todo e é justamente nesse modus operandi o problema central concernente a decadência do homem moderno, do qual Nietzsche defini como 'doença'.

Nietzsche sustenta a existência de um sintoma que promove a decadência política do homem moderno, porém este sintoma é resultado de algo mais elementar mais fundamental, sendo a decadência do próprio homem. A supervalorização do Estado, o predomínio tanto das "ideias modernas" quanto dos "ideais democráticos" que são exigências do pensamento igualitário/democrático contra toda ideia de "privilégio" ou de "direitos" particulares, implica na decadência humana em todos seus aspectos, culturais, estéticos e principalmente morais. A decadência seria o resultado de um processo no qual os valores humanos estão assentados num além-mundo, em suma são estritamente metafísicos inviabilizando, segundo Nietzsche a possibilidade do Humano satisfazer suas potencialidades. $\mathrm{O}$ valor atribuído à compaixão, ao altruísmo contra todo egoísmo, contribui para fazer do homem um "animal de rebanho" (JGB/BM §202). A democracia vigente na Europa é entendida por Nietzsche "não somente uma forma de decadência da organização política, mas uma forma de decadência, isto é, de diminuição do homem, de sua mediocrização e de rebaixamento de seu valor [...]” (JGB/BM §203). Nesse sentido, podemos elucidar essa problemática com uma analogia entre doença e sintoma/causa; o sintoma segundo o filósofo pode ser entendido como a manutenção e supervalorização dos valores democráticos ocasionando a doença do homem moderno, seu apequenamento e 'castração' de suas potencialidades. Segundo Nietzsche o filósofo necessita radicalizar essa questão, fornecendo a fonte do sintoma, nesse caso os supostos "ideais" políticos que apenas prolongaram os "valores eternos" conduzindo à decadência do homem. Dessa forma, no que concerne a esfera política, esta não deve ser mais considerada como um domínio plenamente autônomo, tendo um sentido próprio, um télos como uma potência de transformação do homem, no sentido de melhorá-lo, mais ainda, de conduzi-lo a boa convivência ou a alguma 'paz perpétua'. Em Nietzsche o campo público deve ser apenas considerado como símbolo para avaliar o complexo dos valores basilares constituinte, do que Nietzsche denomina como "complexo de cultura". 


\section{Considerações sobre a 'grande política'}

Para superar a 'doença' diagnosticada da cultura ocidental, Nietzsche não exige somente pensar "um aquém da comunidade política, mas ele nos convida, pelo contrário, a refletir um além: se é preciso, por um lado, pensar menos que o Estado (os indivíduos, sua hierarquia), é preciso também pensar mais que o Estado" (DENAT, 2013, p. 63), ou seja, a Europa. Tal continente que compartilha valores platônicos/cristãos semelhantes, dentre os quais as diferenças entre as nações são meramente aparentes. Os esforços de Nietzsche e sua reflexão impedem a recusa de toda forma de política convencional perscrutada pela tradição filosófica. Nietzsche exige o surgimento de uma "grande política" (JGB/BM §208) englobando o domínio subterrâneo instintivo/pulsional formadores de toda e qualquer ação humana, ou seja, o vir-a-ser do homem.

A proposta de Nietzsche implica pensar um sentido radicalmente novo em política, que carece de um aprofundamento que o próprio filósofo não forneceu em seus escritos. Contudo pode-se abordar essa questão doravante o que foi publicado pelo pensador, e isso requer adentrarmos em duas concepções caras a filosofia nietzschiana, a saber as noções de hierarquia e "natureza aristocrática".

No que concerne a hierarquia esta vincula-se a noção de vontade de potência7, essencial no entendimento do pensamento nietzschiano. Em O Anticristo o filósofo indica essa relação de como os indivíduos melhor se organizaram no interior de uma comunidade ao afirmar

Estabelecer um código como o de Manu significa conceder a um povo, a partir de então, que ele venha a tornar-se mestre, tornar-se perfeito - ambicionar a suprema arte da vida. Para isso, deve ser tornado inconsciente: eis a finalidade de toda mentira sagrada. - A ordem das castas, a lei suprema, dominante, é apenas a sanção de uma ordem natural, de leis naturais66 de primeira categoria, sobre as quais nenhum arbítrio, nenhuma "ideia moderna" tem poder. Em toda sociedade sã se distinguem, condicionando um ao outro, três tipos de diferente gravitação fisiológica, dos cada um tem sua própria higiene, seu próprio âmbito de trabalho, sua própria espécie de mestria e sentimento de perfeição. A natureza, e não Manu, é

\footnotetext{
${ }^{7}$ A vontade de potência possui uma importância basilar no pensamento de Nietzsche. Através deste conceito o filósofo propõe uma nova concepção de mundo, ou seja, uma nova proposta de compreender o todo existente e a existência humana sob um único registro intitulado pelo filósofo de vontade de potência. O filósofo alemão introduz tal conceito na obra Assim falava Zaratustra; nesta obra Nietzsche vinculava a vontade potência apenas ao mundo orgânico; entretanto no fim do período tardio de sua atividade intelectual, Nietzsche sustentava que até mesmo o mundo inorgânico é repleto de vontade de potência. Assim, o domínio dos seres vivos, bem como a esfera do que chamamos de "matéria", segundo o filósofo, é repleto de vontade de potência. Nietzsche assim torna admissível a possibilidade de inserir na filosofia um conceito, abrangente o suficiente com a pretensão de esclarecer o todo existente, desde o orgânico ao inorgânico que são segundo Nietzsche, expressões da vontade de potência.
} 
que separa os predominantemente espirituais, os predominantemente fortes em músculo e temperamento, e os que não se destacam nem de uma maneira nem de outra, os medíocres - estes sendo o grande número, e os dois primeiros, a elite" (AC/AC §57).

Deve-se salientar ainda que a noção de hierarquia em Nietzsche não possui nenhum vínculo com qualquer tipo de pensamento que sustente a igualdade de todos. Tal noção está associada a uma hierarquização de 'espíritos' da ordem do natural, obedecendo a dinâmica do vir-a-ser, formando aquilo que Nietzsche denomina de 'natureza aristocrática do espírito'. E aqui é mister outro esclarecimento, a fim de precaver equívocos interpretativos. A noção de aristocracia em Nietzsche não diz respeito a um indivíduo forte financeiramente, como comumente pode ser entendido, uma vez que, aristocrata, nobre, forte e afirmador possuem o mesmo grau de equivalência no pensamento do filósofo; então qualquer tentativa interpretativa de remeter o nobre nietzschiano a uma concepção envolvendo instâncias do mundo capital/financeiro, incorre em grosseiro erro interpretativo dos escritos de Nietzsche; o mesmo ocorre em associar esse pensamento a um tirano ou qualquer forma de imposição patriarcal. $\mathrm{O}$ aristocrata nobre nietzschiano vincula-se com um tipo de indivíduo fisiologicamente forte o bastante, capaz de assimilar diversas formas de perspectivas, sem recair no assim chamado ressentimento, trata-se de pensar uma cultura forte, elevada e aristocrática. A noção de aristocracia, em outras palavras, não designa aqui simplesmente um modo de organização política, mas certo tipo de valores assumidos que induz nos indivíduos e em relação a eles uma forma de pensamento e de comportamento que poderia finalmente se manifestar, entre outros, no campo político. Dessa forma a hierarquia em Nietzsche, abarca e engloba as noções de aristocracia e fisiologia, estando todas essas noções inter-relacionadas; aqui brevemente esclarecidas.

Outro fator determinante na composição da noção de 'grande política' em Nietzsche é sua noção cultura. Para o filósofo somente no interior de uma cultura forte hierarquicamente estruturada a grande política pode emergir, não como algo pensado/deliberado, mas surge do íntimo cultural de forma natural. A rigor Nietzsche inverte o processo como compreendemos atualmente, uma vez que, a cultura é estabelecida por diretrizes políticas das mais variadas formas de governo, para o filósofo essa abordagem deve ser invertida, a política estrutura-se de acordo com a cultura; é em decorrência do aspecto cultural de um povo que o domínio político surge. A política entendida pelo filósofo é apenas a expressão de determinado tipo de valores estabelecidos pela cultura, onde a possível modificação para esse registro político apenas resulta da transformação das concepções políticas vigentes, por meio da assimilação e incorporação de valores que não os usuais. $O$ questionamento acerca dessa problemática implica esclarecer como um âmbito 
político dominado por séculos pelos valores democráticos, seria capaz de remodelar a forma de pensar sua esfera política e cultural, nos moldes como pretende Nietzsche?

Para responder essa questão, o filósofo aponta que tal tarefa não pode ser realizada de forma repentina ou abrupta, isenta de uma revolução brutal: tal mudança deve satisfizer um processo de longo prazo:

É necessário administrar o remédio em doses menores, mas incansavelmente e por longos períodos! O que se pode criar de grande de uma só vez! Nós nos guardamos, dessa forma, de trocar, com precipitação e violência, por uma nova apreciação de valor das coisas, o estado da moral que estamos habituados - não, queremos continuar a viver por muito tempo nesse estado antigo - até que, provavelmente bem depois, nós tenhamos no dado conta que a nova apreciação de valor se tornou, em nós, a potência preponderante e que as pequenas doses, às quais devemos nos habituar desde agora, colocaram em nós uma nova natureza (M/A §534).

A filosofia nietzschiana, como exposto, não se vincula a uma filosofia estritamente destrutiva; ao contrário, ao rejeitar a "precipitação e violência", às perigosas "tentativas destrutivas", Nietzsche pensa um modo de alternância e de substituição a longo prazo. Essa fórmula pode ser encontrada na de Gaia ciência, onde afirma: "é somente enquanto criadores que podemos aniquilar!" (FW/GC \$58). Porque não se pode criar nada de grande de uma só vez, "uma lógica da transformação e da lenta re-criação se revela necessária. Ora, uma tal lógica de recriação não pode se efetivar a partir do nada" (DENAT, 2013, p. 67). Tal perspectiva implica as circunstâncias políticas/culturais vigentes atualmente, "para que surjam os filósofos legisladores do amanhã, os espíritos livres que devem refletir sobre "as condições para o seu surgimento, que deveriam em parte criar, em parte explorar", e, para sua obra de cultivo [élevage], o filósofo deve saber usar também "as condições políticas e econômicas de sua época" (JGB/BM §203). A "grande política" não se vincula a um "programa" sistematicamente determinado, ela resulta de uma forma de cultura onde a política seria uma instância resultante do modo como tais indivíduos vivem, não possuindo o caráter de estado democrático liberal, no sentido mais forte do termo. Em conformidade com seu pensamento, apesar de Nietzsche não ser sistemático, seus escritos compõem um corpus filosófico coerente. Isto fica claro ao compararmos outros dois conceitos importantes em Nietzsche com a reflexão política, a saber a pequena razão e a grande razão; analogamente a primeira vincula-se a 'pequena política' possuindo como diretriz básica a manutenção dos valores democráticos, ordenados pelo pensamento estritamente racional; a segunda diz respeito a 'grande política e envolve o aspecto pulsional das ações e mesmo a próprio constituição fisiológica dos indivíduos, sem a necessidade de recorrer a deliberações ou a racionalidade prática no agir, ou seja, a 'grande política' engloba o 
aspecto pulsional na hierarquização da sociedade sob o registro do necessário ${ }^{8}$, sendo fruto da constituição de seus indivíduos em decorrência de certa cultura forte.

O caráter "antipolítico" da reflexão nietzschiana deve ser considerada enquanto recusa da tradicional visão política existente desde a modernidade, visando a 'grande política'. Nesse sentido para questionar os valores dos quais Nietzsche está inserido, o filósofo se distancia desse contexto político, contudo, não se exclui definitivamente dessa mesma comunidade, pois é preciso que deva ter relações com a mesma para melhor lhe interrogar, estando "fora do comum"; "da mesma forma que o médico não poderia fugir de seus doentes e da doença, o filósofo deve estabelecer relação com aquilo mesmo que ele pretende colocar em questão para avaliar" (DENAT, 2013, p. 52). Se Nietzsche tenciona estar de certa forma "afastado" do domínio político, ou seja, não se submeter aos valores vigentes, tal "afastamento" só pode ser relativo; deve ser a condição de possibilidade da interpelação filosófica, e não o olvidamento e a repulsa absoluta concernente a questão política.

Nietzsche pretende radicalizar a discussão entorno da política estendendo sua significação em prol da "grande política" superando as noções de Estado, de nação, ou ainda de poder político que compõe a 'pequena política', vigentes no ocidente de modo a estabelecer uma reflexão acerca das possibilidades de uma legítima transformação da comunidade humana, entendida em seu sentido mais amplo, mais natural. Na história podemos averiguar que certos valores atualmente reconhecidos como verdadeiros não existiam em épocas de outrora; a palavra 'culpa' e livrearbítrio sequer existiam no contexto Grego, por exemplo, e mesmo em outras culturas antigas não há indícios da existência dessas terminologias e de suas efetividades no âmbito prático ou político. Para Nietzsche tais valores foram introjetados na cultura através do longo processo de moralização do ocidente após a queda do império romano, promovida especialmente pela interpretação judaica/cristã de mundo, com todos os valores eternos e imutáveis que o sustentam,

\footnotetext{
${ }^{8} \mathrm{O}$ necessário para Nietzsche envolve a impossibilidade da contingência, pois se configura a partir da vontade de potência, onde, cada centro de força é estabelecido em relação a outros centros de força, inexistindo um evento ao acaso Conforme o fragmento póstumo, onde Nietzsche sustenta a impossibilidade de um evento acontecer pela contingência ou pelo caos, afirmando que "a absoluta necessidade de um mesmo acontecer em um processo cósmico, como em todos os demais, por toda a eternidade, não é um determinismo acerca do acontecer, mas meramente a expressão de que o impossível não é possível... de que uma força determinada não pode ser nenhuma outra coisa que não precisamente essa força determinada; de que ante um quantum de resistência de força não se expressa de outro modo que não como correspondente a sua própria força - acontecer e acontecer necessário são uma tautologia." (Naschlass/FP Outono de 1887, 10[138]). Não se pode confundir o significado concedido pelo filósofo a sua concepção de necessário, como algo previamente estabelecido dotado de uma intencionalidade externa ao mundo, concebidos por artífices como: Deuses, o Demiurgo platônico, o Gênio maligno cartesiano ou O Absoluto de Hegel ${ }^{8}$, por exemplo.
} 
a saber: a igualdade, liberdade, responsabilidade, culpa, justiça, compaixão, caridade, fraternidade, bondade e maldade, ou seja, valores gregários decadentes.

Do mesmo modo que o filósofo ao criticar a Filosofia coloca-se a par da mesma, ou seja, mantém um afastamento da concepção tradicional filosófica, sem, entretanto, renunciar a ser filósofo. Nietzsche sustenta que para criticar a significação usual da política, todo filósofo preocupado com essa temática deve se afastar de seu próprio contexto político, pois assim pode refletir profundamente as condições políticas no qual está inserido, em suma: para Nietzsche, o filósofo deve ser compreendido como aquele indivíduo caracterizado como antipolítico, se este pretender um pensamento autenticamente político, isento de valores decadentes.

\section{Referências bibliográficas}

ANSELL-PEARSON, Keith. Nietzsche como pensador político: uma introdução. Rio de Janeiro: Jorge Zahar, 1997.

AZEREDO, Vânia Dutra de. "Eticidade do Costume: A Inscrição do Social no Homem”. In: Dissertatio n.25. p. 73-90. Pelotas: UFPel, 2007.

BENOIT, Blaise. "Nietzsche e a ordem moral do mundo: genealogia de uma tradução de tradução". In: O mais potente dos afetos: Spinoza e Nietzsche. p. 212-232. André Martins (org.). São Paulo: Martins Fontes, 2009.

BRUSOTTI, Marco. “Tensão: um conceito para o grande e para o pequeno”. Trad. Rogério Lopes. In: Dissertatio, n.33. Pelotas, inverno de 2011. p.35-62.

DENAT, Céline. F. Nietzsche ou a "política" como "antipolitica". In. Cadernos Nietzsche n.32. p. 41-71. São Paulo: GEN, 2013.

FREZZATTI, Wilson. A Fisiologia de Nietzsche: a Superação da Dualidade Cultura/Biologia. Ijuí: Editora UNIJUÍ, 2006.

ITAPARICA, André. Nietzsche: Estilo e moral. São Paulo: Discurso Editorial, 2002.

NIETZSCHE, Friedrich. Obras Incompletas. Seleção de textos de Gerárd Lebrun; tradução e notas de Rubens Rodrigues Torres Filho. $1^{\underline{a}}$ ed. São Paulo: Nova cultural, 1974 (Col. "Os Pensadores").

. Humano, demasiado humano. Um livro para espíritos livres. Tradução, notas e posfácio Paulo César de Souza. São Paulo: Companhia das letras, 2000.

Aurora: Reflexões sobre preceitos morais. Tradução, notas e posfácio Paulo César de Souza. São Paulo: Companhia das letras, 2004.

. A gaia ciência. Tradução, notas e posfácio Paulo César de Souza. São Paulo: Companhia das letras, 2001. 
Além do Bem e do Mal. Tradução de Mario Ferreira dos Santos. Petrópolis:

Vozes, 2009.

. Crepúsculos dos Ídolos. Ou de como filosofar com o martelo. Tradução, notas e posfácio Paulo César de Souza. São Paulo: Companhia das letras, 2006.

Fragmentos póstumos (1869-1875) (Vol. I). Edición española dirigida por Diego Sánches Meca. Madrid: Editorial Tecnos (Grupo Anaya, S. A.), 2008.

Fragmentos póstumos (1885-1888) (Vol. IV). Edición española dirigida por Diego Sánches Meca. Madrid: Editorial Tecnos (Grupo Anaya, S. A.), 2008.

MARTON, Scarlett. Das forças cósmicas aos valores humanos. São Paulo: Brasiliense, 2010.

WOTLING, Patrick. Nietzsche e o problema da civilização. Tradução de Vinicius de Andrade. São Paulo: GEN/Editora Barcarolla, 2013.

— Vocabulário Nietzsche. Trad. Claudia Berliner. São Paulo: Martins Fontes, 2011.

Submissão: 30.09.2016 / Aceite: 25.10.2016 